\title{
Effects of Different Lightweight Functional Fillers for Use in Cementitious Composites
}

\author{
Asad Hanif* ${ }^{\circ}$, Zeyu Lu, Yu Cheng, Su Diao, and Zongjin Li
}

(Received August 13, 2016, Accepted November 21, 2016, Published online February 8, 2017)

\begin{abstract}
The effects of different lightweight functional fillers on the properties of cement-based composites are investigated in this study. The fillers include fly ash cenospheres (FACs) and glass micro-spheres (GMS15 and GMS38) in various proportions. The developed composites were tested for compressive, flexural and tensile strengths at 10 and 28 -day ages. The results indicated that both FACs and GMS38 are excellent candidates for producing strong lightweight composites. However, incorporation of GMS15 resulted in much lower specific strength values (only up to $13.64 \mathrm{kPa} / \mathrm{kg} \mathrm{m}^{3}$ ) due to its thinner shell thickness and lower isostatic crushing strength value (2.07 MPa). Microstructural analyses further revealed that GMS38 and GMS15 were better suited for thermal insulating applications. However, higher weight fraction of the fillers in composites leads to increased porosity which might be detrimental to their strength development.
\end{abstract}

Keywords: functional fillers, cement, composites, cenosphere, glass microsphere, mechanical properties, porosity.

\section{Introduction}

Lightweight concrete (LWC) has gained much more interest from the researchers in the last few decades although its use could trace back to $3000 \mathrm{BC}$ (Chandra and Berntsson 2002). The reasons for such increased interest are its unique advantages over normal weight concrete such as reduction in dead loads leading to smaller structural member as well as foundation size, ease of the shipping and transportation in case of precast structural members, and reduced overall construction cost. In addition LWC offers excellent durability in chemical and frost attack with reduced permeability (Li 2011), greater fire resistance (ACI 216.1 1997) and better thermal insulation (ACI 213 2003). The unit weight of LWC lies in the range of $1200-1800 \mathrm{~kg} / \mathrm{m}^{3}$ (Li 2011) while for structural LWC in general ACI Committee 213 defines the range as $1120-1920 \mathrm{~kg} / \mathrm{m}^{3}$ (ACI 213 2003). In order to achieve the desired unit weight with adequate mechanical properties, careful selection and efficient utilization of lightweight filler (LWF) materials is imperative.

Traditionally, different types of LWFs have been studied for their use in the cement-based composites such as expanded perlite (Demirboğa et al. 2001; Kramar and Bindiganavile 2010; Lanzón and García-Ruiz 2008; Lu et al. 2014), expanded glass beads (ASTM D790-10 2010;

Department of Civil and Environmental Engineering, The Hong Kong University of Science and Technology, Kowloon, Hong Kong.

*Corresponding Author; E-mail: ahanif@connect.ust.hk

Copyright $($ The Author(s) 2017. This article is published with open access at Springerlink.com
Bouvard et al. 2007), shale (de Gennaro et al. 2008; Ke et al. 2009; Lotfy et al. 2015), expanded polystyrene beads (Bouvard et al. 2007; Miled et al. 2007; Saradhi Babu et al. 2005), expanded clay (Chandra and Berntsson 2002; Gao et al. 2014) etc. and the unit weight has been successfully achieved within the stipulated guidelines. However such composites had lower mechanical strength and reduced overall performance. For example $\mathrm{Yu}$ et al. used recycled expanded glass and achieved 28-day density of the composites as low as $1280 \mathrm{~kg} / \mathrm{m}^{3}$ with good durability, however, the corresponding compressive strength was limited to 23.3 MPa (Spiesz et al. 2013; Yu et al. 2013). Also, Chen and Liu developed expanded polystyrene foam composite with density of 400 and $800 \mathrm{~kg} / \mathrm{m}^{3}$ with excellent thermal insulation properties (lower thermal conductivity coefficient) but the extremely low corresponding strength values of 3 and $13 \mathrm{MPa}$ hampered the use in structural applications (Chen and Liu 2013). Similarly, Topku and Isikdag used perlite aggregate as LWF and produced the composites within the density range of $1800-2040 \mathrm{~kg} / \mathrm{m}^{3}$ and deduced that any amount of perlite aggregate greater than $30 \%$ has negative effects on the parameters relating to mechanical strength. Even at $1800 \mathrm{~kg} / \mathrm{m}^{3}$ density, the strength was limited to $37.3 \mathrm{MPa}$ (Topçu and Işıkdağ 2008). Kramar and Bindiganavile further confirmed that compressive strength declines cubically while flexural strength and fracture toughness decreases linearly with perlite addition (Kramar and Bindiganavile 2013). Mladenovic studied the expanded vermiculite, clay, glass and perlite and similar observations for alkali-silica reactivity and found that these LWFs are suitable in terms of this particular durability related property (Ducman and Mladenovic 2004). Likewise, Hassanpur et al. comprehensively reviewed the problems associated with the 
use of LWFs (expanded perlite, expanded clay, pumice, etc.) in cementitious composites and concluded that inclusion of different kinds of fibers may significantly improve the toughness, ductility and energy absorption of the resulting composites, however the lower mechanical strength (compressive strength) remains an unresolved issue (Hassanpour et al. 2012).

In the recent years, researchers have also been trying to investigate some other materials like cenosphere (ChávezValdez et al. 2011; Kwan and Chen 2013; Pichór 2009; Wang et al. 2012, 2013; Wu et al. 2015; Xu et al. 2015) and aerogel particles (Gao et al. 2014; Hanif et al. 2016; Kim et al. 2013; $\mathrm{Ng}$ et al. 2015) for their use as LWF. Xu et al. found that even though incorporating cenosphere in magnesium oxy-chloride cement composite reduces the compressive strength, still high levels of strength (60 MPa) are achieved (Xu et al. 2015). Similar findings for cenosphere particles in OPC based composites were presented by Wang et al. $(2012,2014)$ and $\mathrm{Wu}$ et al. (2015). This indicates their potential for producing strong lightweight composites. Further, the studies carried out on the influence of aerogels by Hanif et al. (2016) and Ng et al. (2015) showed that aerogel is ideally suited for thermally insulated composites while the mechanical strength is not high enough because of the mechanical properties of aerogel particles (Woignier and Phalippou 1988).

Nevertheless, the need to broaden the knowledge on cenosphere behavior in the cement-based composites is still increasing. Moreover, alternate LWFs need to be sought for improved properties of the resulting composites. Although various fillers have been previously used, the objective of getting the reduced unit weight at adequate strength levels is still challenging (Sharifi et al. 2016). The aim of current study is to evaluate the properties of the composites with incorporation of an alternative lightweight material, the hollow glass microspheres, and comparing the resulting properties with cenosphere incorporated composites.

\section{Experimentation Program and Materials}

\subsection{Materials}

Ordinary Portland cement (type 52.5; conforming to ASTM type I), supplied by Hong Kong Green Island Cement Ltd. and locally available silica fume were used in the experimentation program. Cement and silica fume altogether comprised the binder. Silica fume was employed for enhanced packing properties of the resulting composites (Mala et al. 2013; Rashad et al. 2014). Lightweight Functional fillers (Fig. 1); fly ash cenosphere (FAC) and glass microspheres (GMS15 and GMS38) were provided by Zhen Yang, Hebei China, and 3M Hong Kong Limited, respectively. Table 1 enlists the physical properties of the various fillers evaluated in this paper whereas their particle size distribution (acquired by laser granulometry) is plotted in Fig. 2. PVA fibers were also incorporated into the mix to enhance the flexural performance of the composites (Abbas et al. 2016). The PVA fibers used were $39 \mu \mathrm{m}$ (diameter) $\times 15 \mathrm{~mm}$ (length). The fibers used had tensile strength of $1600 \mathrm{MPA}, 6 \%$ elongation and $41 \mathrm{GPa}$ Young's modulus. The elemental analysis of the raw materials, including binders and fillers, was done to quantify the chemical compositions. For this purpose, X-ray fluorescence spectrometry (XRF) was carried out whose results were listed in Table 2. A significant amount of silica was present in all of the filler materials. Furthermore, GMS15 and GMS38 contained significantly higher amount of lime as compared to FAC while the other oxide compositions were almost similar. As shown in Table 1, specific surface area results (obtained using
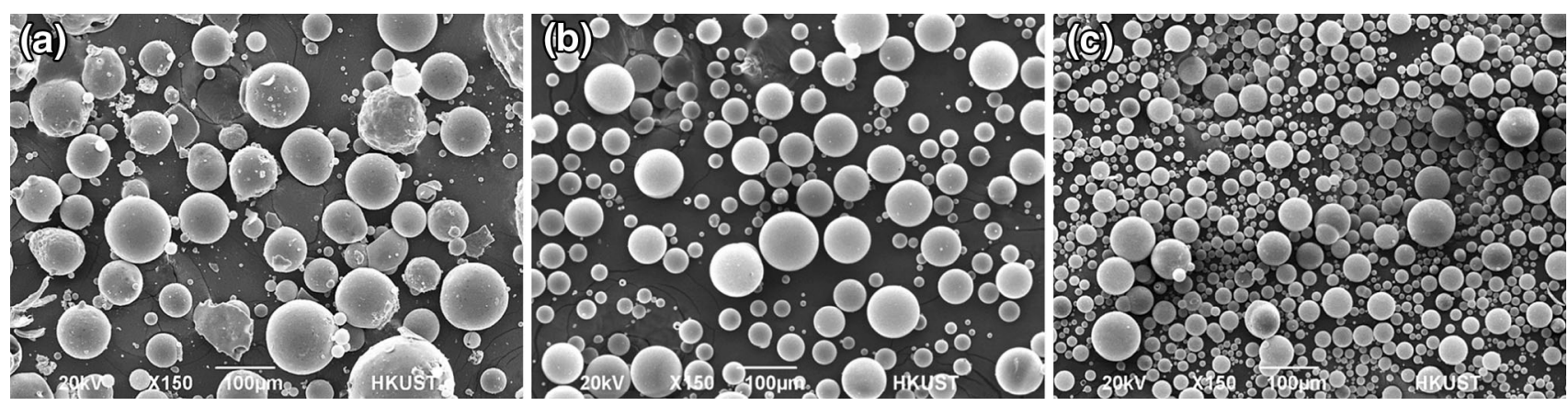

Fig. 1 Scanning electron microscopic images of different functional fillers used in the study a FAC, b GMS15, and c GMS38.

Table 1 Physical characteristics of lightweight fillers.

\begin{tabular}{c|c|c|c|c}
\hline Description & Bulk density $\left(\mathrm{kg} / \mathrm{m}^{3}\right)$ & BET surface area $\left(\mathrm{m}^{2} / \mathrm{g}\right)$ & Color & $\begin{array}{c}\text { Iso-static crush strength } \\
(\mathrm{MPa})\end{array}$ \\
\hline \hline Glass micro-sphere GMS15 & 150 & 35.62 & White & 2.07 \\
\hline Glass micro-sphere GMS38 & 380 & 95.71 & White & 27.58 \\
\hline Fly ash cenosphere & 720 & 6.02 & Grey & $70-140$ \\
\hline
\end{tabular}

${ }^{a}$ Isostatic crush strength denotes the stress at which the average bulk of material has $90 \%$ or greater survival. (3M energy and advanced materials division 2007). 


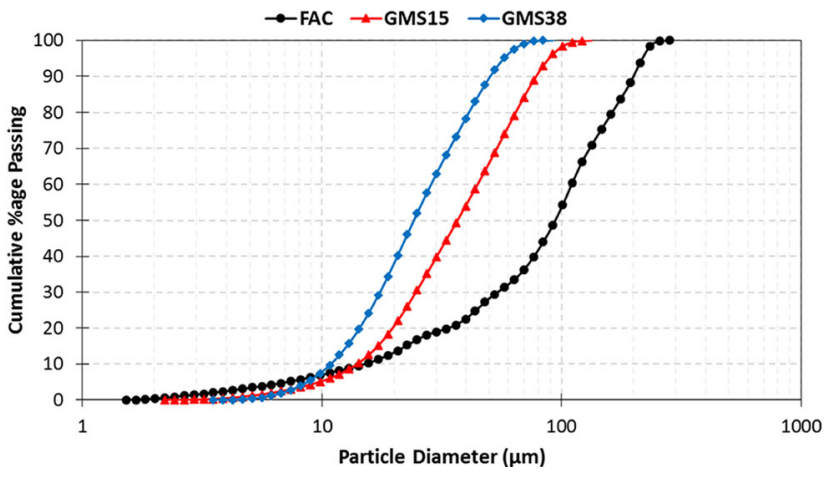

Fig. 2 Particle size distribution of LWFs used; FAC, GMS15, and GMS38. (Color figure online).

Coulter SA 3100) showed that GMS15 and GMS38 possessed higher area to weight ratio which indicated their suitability for making lightweight composites, however the shell thickness determined the stress these particles can endure. Particle size has an inverse correlation with the specific surface area, as elaborated by Palik (Palik 1977) as well as by Lowell and Shields (Lowell and Shields 1991), meaning that the smaller the particle size, the higher the surface area. The results in Table 1 were found in agreement with the correlation.

\subsection{Mix Proportions and Specimen Casting}

The mix proportions, incorporating different weight fractions of lightweight fillers, are given in Table 3. Control mix, without incorporating any filler material, was also prepared. The flowability and cohesiveness of the mixtures were achieved by varying the water content and using a polycarboxylate ether based admixture (ADVA 105 by Grace Canada Inc.) whereas to achieve good packing characteristics, $10 \%$ silica fume (by weight of binder) was also employed. The amounts of water and super-plasticizer were adjusted to get slump flow of 180-200 mm. The slump flow test was done in accordance with ASTM C230 and C1437 (ASTM C230 2003; ASTM C 1437-99 1999). The mixing was done in a Hobart mixer of $10 \mathrm{~L}$ capacity and comprised of mixing of all the dry powders followed by the water addition while constantly mixing until the uniformity of mix is observed. Later, the admixture and fibers were added. After fiber addition, the mixture was stirred both at low and high speed levels to enable uniformity of fibers in the mixed slurry. The complete mixing process took about $10 \mathrm{~min}$.

The mixed fibrous pastes were cast into the pre-lubricated steel molds and compacted for removing the entrapped air. Specimen prisms (Area $40 \mathrm{~mm} \times 40 \mathrm{~mm}$ and length $160 \mathrm{~mm}$ ) and cubes (40 mm side) were cast for testing strength in flexure and compression, respectively. The tensile strength test specimen size was $50 \mathrm{~mm} \times 15 \mathrm{~mm}$ (area) and $350 \mathrm{~mm}$ (length). After casting, the specimens were wrapped using a plastic sheet and kept under room temperature. After one day, the specimen were demolded and retained in the curing room where the relative humidity and temperature were maintained at $95 \%$ and $25^{\circ} \mathrm{C}$, respectively. The curing of the specimen was continued till their testing age. Mechanical strength parameters were tested after 10 and 28 days while the microstructural studies were carried out after 28-day age.

\subsection{Experimental Methods and Procedures 2.3.1 Mechanical Testing}

The mechanical tests included compression, flexure, and tension. Compressive strength testing was conducted in an automatic compression testing machine, at the loading rate of $1.0 \mathrm{kN} / \mathrm{s}$. Three-point bending test was done on the with the span length of $100 \mathrm{~mm}$ and the loading rate of $0.15 \mathrm{~mm} /$ min. Load at mid-point was directly recorded whereas the mid-span deflection was measured with two LVDTs (linear variable differential transformers) attached parallelly on the specimen. The load and deflection values were used to develop stress-strain plots. Moreover, the elastic modulus was also determined. For determining the tensile strength, direct tension tests on the relevant specimen were done with a length of $150 \mathrm{~mm}$ in testing portion and the loading of $0.05 \mathrm{~mm} / \mathrm{min}$. Extension in the specimens was measured with two LVDTs mounted on the specimen in the direction parallel to the loading direction. For all the mixes, three specimen were tested for each property under investigation and the average of these were reported for corresponding test.

Following equations were used for determining flexural stress, strain (ASTM D790-10 2010) and elastic modulus (ACI Committee 318 2007):

Table 2 Elemental analysis of the raw materials.

\begin{tabular}{c|c|c|c|c|c|c|c|c|c|c}
\hline Description & $\mathrm{Al}_{2} \mathrm{O}_{3}$ & $\mathrm{CaO}$ & $\mathrm{SiO}_{2}$ & $\mathrm{SO}_{4}$ & $\mathrm{Fe}_{2} \mathrm{O}_{3}$ & $\mathrm{Na}_{2} \mathrm{O}$ & $\mathrm{K}_{2} \mathrm{O}$ & $\mathrm{TiO}_{2}$ & $\mathrm{MnO}$ & $\mathrm{MgO}$ \\
\hline \hline Cement & 3.86 & 65.41 & 19.47 & 5.72 & 3.21 & - & 0.50 & 0.26 & - & 1.58 \\
\hline $\begin{array}{c}\text { Fly ash } \\
\text { cenospheres }\end{array}$ & 16.70 & 1.06 & 73.10 & 0.42 & 1.96 & 2.42 & 3.94 & 0.35 & 0.05 & - \\
\hline Silica fume & - & 0.78 & 98.45 & 0.41 & 0.05 & - & 0.31 & - & - & - \\
\hline $\begin{array}{c}\text { Glass- } \\
\text { microsphere } \\
\text { GMS15 }\end{array}$ & - & 10.76 & 81.63 & 0.55 & - & 5.97 & - & - & - & - \\
\hline $\begin{array}{c}\text { Glass- } \\
\text { microsphere } \\
\text { GMS38 }\end{array}$ & - & 12.95 & 77.95 & 0.38 & - & 7.69 & - & - & - & - \\
\hline
\end{tabular}




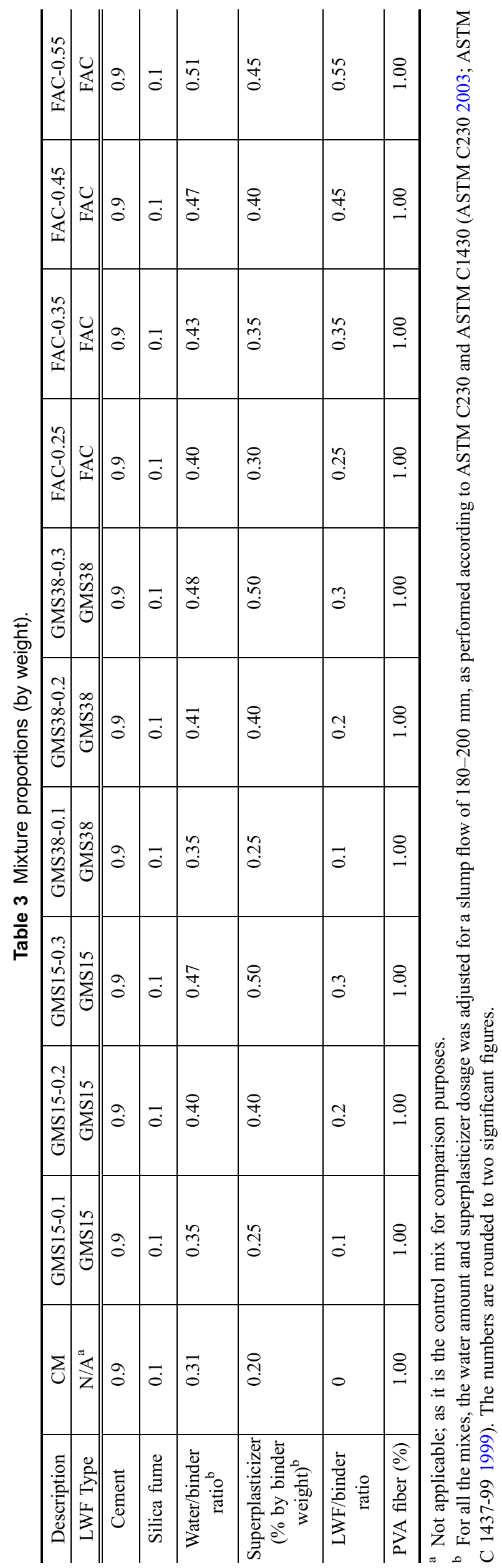

$$
\begin{aligned}
\sigma_{f} & =\frac{3 P L}{2 b d^{2}} \\
\varepsilon_{f} & =\frac{6 D d}{L^{2}} \\
E_{c} & =W_{c}^{1.5}(0.043) \sqrt{\lambda f_{c}^{\prime}}
\end{aligned}
$$

where, $\sigma=$ stress in the outer fibers at midpoint, $\mathrm{MPa}$; $\varepsilon=$ strain in the outer surface, $\mathrm{mm} / \mathrm{mm} ; P=$ load at a given point on the load-deflection curve, $\mathrm{N} ; b=$ width of beam tested, $\mathrm{mm} ; d=$ depth of beam tested, $\mathrm{mm} ; D=$ maximum deflection of the center of the beam, mm, and; $E_{c}=$ modulus of elasticity of concrete, $\mathrm{MPa} ; W_{c}=$ density (unit weight) of concrete, $\mathrm{kg} / \mathrm{m}^{3} ; f_{c}^{\prime}=$ compressive strength of concrete, $\mathrm{MPa}$, and; $\lambda=$ modification factor reflecting the reduced mechanical properties of lightweight concrete.

\subsubsection{Testing for Morphological and Microstruc- tural Characterization}

Microstructural studies were carried out by using scanning electron microscopy (SEM) in which hydration products identification, observation of LWF particle distribution in the matrix, and evaluation of pore structures were done. SEM was done with the help of JSM-6390 and JSM-6700F (ultra-high resolution scanning electron microscope; $1 \mathrm{~nm}$ at $15 \mathrm{kV}$ and $2.2 \mathrm{~nm}$ at $1 \mathrm{kV}$ ) (Jeol USA Inc.). Also, thermogravimetric and differential thermal analysis (using TGA Q5000 and TG/DTA 92 Setaram II) methods were employed for determining the heat flow and weight change (phase transformation) with temperature. For this purpose, samples were prepared by grinding the broken pieces at 28-day age, and subjected to heating from room temperature to $900{ }^{\circ} \mathrm{C}$ at the rate of $10{ }^{\circ} \mathrm{C}$ per minute, under nitrogen environment (nitrogen flow rate of $25.00 \mathrm{~mL} / \mathrm{min}$ and inlet gas pressure 1 bar). The corresponding values of weight loss and heat flow were determined.

Porosity and pore volume characteristics in the composites were evaluated by mercury intrusion porosimetry (MIP) method (Ma and Li 2013). For this test, the samples were prepared by breaking down to smaller sizes and dried by solvent replacement method in which the solvent (ethanol) was changed every $6 \mathrm{~h}$ during the first few days and then every day until one week. Later the specimen were subjected to vacuum drying. The dried samples were subjected to mercury intrusion during which the pressure was increased up to $400 \mathrm{MPa}$ (initially low pressure followed by high pressure). The mercury-concrete contact angle was taken as $140^{\circ}$ (Ma 2014). Washburn equation (Washburn 1921) was used to convert the pressure into relevant pore diameter while Katz-Thompson model (Katz and Thompson 1986) was employed to determine the permeability.

\section{Results, Analyses and Discussion}

\subsection{Density and Compressive Strength}

The saturated surface dry (SSD) density of the specimen determined at the age of 10- and 28-day is shown in Table 4 


\begin{tabular}{|c|c|c|c|c|c|c|c|c|c|c|}
\hline 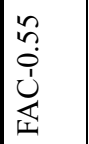 & 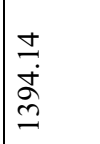 & $\begin{array}{l}\stackrel{+}{+} \\
\text { in }\end{array}$ & 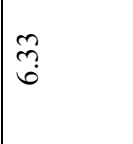 & $\begin{array}{l}n \\
2 \\
i n \\
o n\end{array}$ & 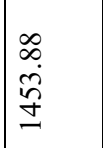 & $\begin{array}{l}\infty \\
\tilde{i} \\
\stackrel{q}{q}\end{array}$ & ڤ̊ & 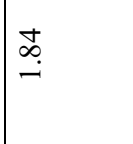 & $\mid \begin{array}{l}0 \\
\infty \\
0 \\
0\end{array}$ & $\stackrel{\sim}{\stackrel{\sim}{\sim}}$ \\
\hline 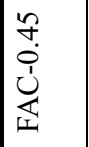 & 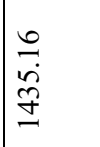 & $\begin{array}{l}\dot{J} \\
\stackrel{f}{f}\end{array}$ & nn & $\begin{array}{l}\hat{\infty} \\
0 \\
0 \\
0\end{array}$ & 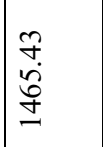 & 年 & $\underset{\square}{\sim}$ & $\stackrel{m}{i}$ & $\mid \begin{array}{l}\qquad \\
\infty \\
o \\
0\end{array}$ & $\stackrel{\tilde{m}}{\tilde{m}}$ \\
\hline 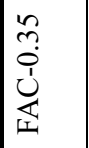 & $\begin{array}{l}\infty \\
\infty \\
i n \\
i n \\
\underline{n}\end{array}$ & $\stackrel{\infty}{\stackrel{\infty}{-}}$ & $\begin{array}{l}\infty \\
\infty \\
\infty \\
\infty\end{array}$ & $\begin{array}{l}\tilde{N} \\
\infty \\
0 \\
0\end{array}$ & $\begin{array}{l}m \\
m \\
\stackrel{f}{f} \\
\stackrel{d}{n}\end{array}$ & $\begin{array}{l}\circ \\
\stackrel{2}{\infty} \\
\infty \\
+\end{array}$ & $\stackrel{8}{\circ}$ & $\hat{n}$ & $\stackrel{g}{\stackrel{g}{m}}$ & $\begin{array}{l}\infty \\
\infty \\
\end{array}$ \\
\hline 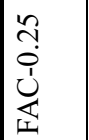 & 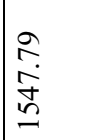 & $\begin{array}{l}8 \\
\text { in } \\
\text { in }\end{array}$ & I̊. & $\tilde{\hat{\sigma}}$ & $\begin{array}{l}\infty \\
\stackrel{\sim}{1} \\
\\
\end{array}$ & $\begin{array}{l}\hat{\sigma} \\
\tilde{n} \\
\text { in }\end{array}$ & $\stackrel{\oplus}{=}$ & $\vec{i}$ & $\begin{array}{l}\stackrel{2}{\infty} \\
\stackrel{-}{-}\end{array}$ & $\begin{array}{l}0 \\
0 \\
0\end{array}$ \\
\hline $\begin{array}{l}n \\
0 \\
1 \\
\infty \\
n \\
n \\
\sum_{0}^{n}\end{array}$ & $\begin{array}{l}\infty \\
\text { m } \\
\stackrel{\varrho}{\Xi} \\
\Xi\end{array}$ & $\underset{I}{\stackrel{I}{I}}$ & 芯 & $\begin{array}{l}\infty \\
\infty \\
\infty \\
0 \\
0\end{array}$ & $\begin{array}{l}\hat{0} \\
\infty \\
0 \\
ٍ \\
=\end{array}$ & $\begin{array}{l}\vec{F} \\
\infty \\
\stackrel{\infty}{0}\end{array}$ & $\begin{array}{l}\infty \\
\infty \\
i\end{array}$ & 훙 & 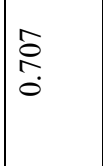 & $\frac{ \pm}{6}$ \\
\hline 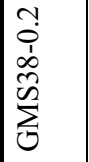 & 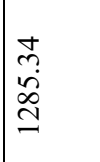 & in & $\stackrel{\infty}{\stackrel{\infty}{n}}$ & 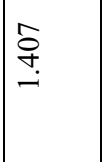 & $\begin{array}{l}\tilde{\lambda} \\
m \\
m \\
m\end{array}$ & 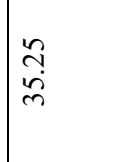 & 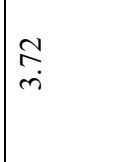 & ó & $\begin{array}{l}\stackrel{0}{2} \\
\vdots \\
0\end{array}$ & 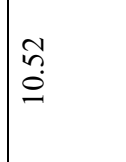 \\
\hline $\begin{array}{l}\overrightarrow{0} \\
0 \\
1 \\
0 \\
\sum_{0}^{n} \\
0\end{array}$ & 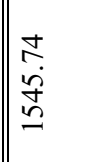 & $\begin{array}{l}\vec{b} \\
\text { in }\end{array}$ & $\begin{array}{l}\infty \\
i \\
i \\
i\end{array}$ & $\frac{n}{b}$ & 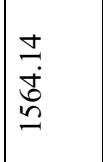 & \begin{tabular}{l}
+ \\
$\stackrel{+}{\sigma}$ \\
\multirow{r}{*}{}
\end{tabular} & $\tilde{b}$ & $\stackrel{\infty}{\infty}$ & 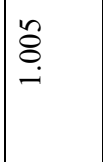 & $\begin{array}{l}6 \\
i \\
2\end{array}$ \\
\hline $\begin{array}{l}n \\
0 \\
1 \\
n \\
\sum_{0}^{n}\end{array}$ & \begin{tabular}{l}
$\hat{n}$ \\
\multirow{n}{N}{} \\
\end{tabular} & 1 & $\begin{array}{l}\infty \\
0 \\
0\end{array}$ & $\begin{array}{l}\text { ते } \\
\text { ठ }\end{array}$ & $\begin{array}{l}\stackrel{\infty}{\infty} \\
\stackrel{\sim}{\sim}\end{array}$ & సి & $\stackrel{\infty}{\stackrel{\infty}{0}}$ & $\stackrel{\tilde{m}}{\tilde{m}}$ & $\stackrel{\vec{r}}{\hat{\sigma}}$ & 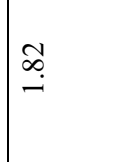 \\
\hline 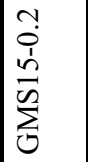 & $\begin{array}{l}n \\
\hat{d} \\
\dot{\alpha}\end{array}$ & 1 & $\stackrel{\text { fq }}{-}$ & $\begin{array}{l}0 \\
\text { on } \\
0\end{array}$ & 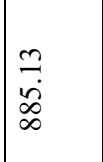 & $\frac{0}{a}$ & $\stackrel{\infty}{\stackrel{\infty}{-}}$ & $\stackrel{\infty}{\stackrel{\infty}{0}}$ & $\begin{array}{l}\hat{\tilde{b}} \\
0 \\
0\end{array}$ & $\hat{a}$ \\
\hline $\begin{array}{l}\overrightarrow{0} \\
\dot{1} \\
\text { ñ } \\
\sum_{0}^{n}\end{array}$ & 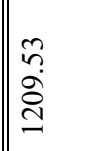 & 1 & $\overline{\widehat{a}}$ & $\begin{array}{l}0 \\
\infty \\
0 \\
0\end{array}$ & $\begin{array}{l}\overrightarrow{0} \\
\stackrel{0}{0} \\
\vdots \\
\end{array}$ & $\underset{I}{I}$ & $\begin{array}{l}\hat{\sigma} \\
\dot{n}\end{array}$ & $\hat{o}$ & $\frac{0}{\stackrel{n}{0}}$ & $\widehat{\infty}$ \\
\hline$\sum$ & $\begin{array}{l}5 \\
0 \\
0 \\
0 \\
i\end{array}$ & $\begin{array}{l}\text { +े. } \\
\stackrel{\infty}{\infty}\end{array}$ & $\stackrel{\tilde{o}}{=}$ & $\begin{array}{l}\tilde{\sim} \\
\stackrel{n}{-}\end{array}$ & 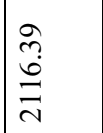 & 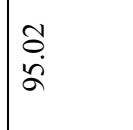 & $\frac{\Delta}{\mathscr{D}}$ & $\begin{array}{l}i n \\
n \\
m\end{array}$ & $\begin{array}{l}\tilde{m} \\
\tilde{m}\end{array}$ & 怂 \\
\hline 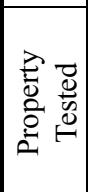 & 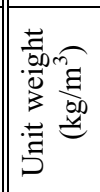 & 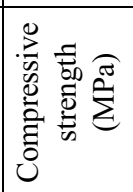 & 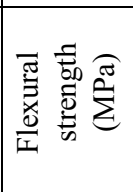 & 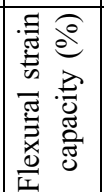 & 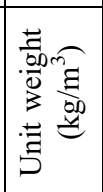 & 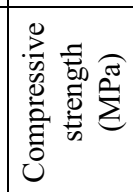 & 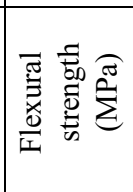 & 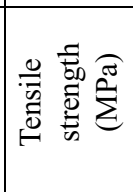 & 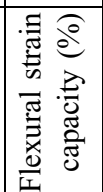 & 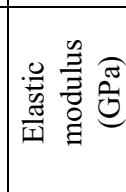 \\
\hline 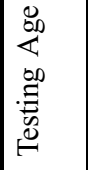 & \multicolumn{4}{|l|}{ 莣 } & \multicolumn{6}{|l|}{ 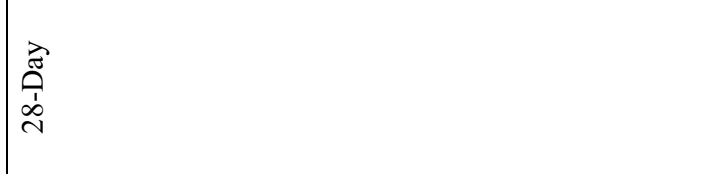 } \\
\hline
\end{tabular}




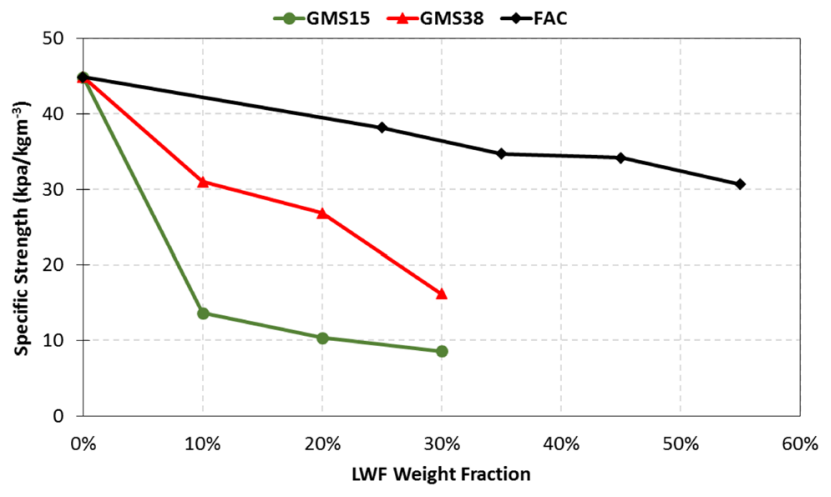

Fig. 3 Specific strength values at 28-day age. (Color figure online).

along with other mechanical properties. 28-Day density ranges from 1256.61 to $734.82,1564.14$ to 1138.07 , and 1551.28 to $1453.88 \mathrm{~kg} / \mathrm{m}^{3}$ for composites incorporating with GMS15, GMS38, and FAC, respectively. Based on the density values, the composites can be classified into ultralightweight and lightweight for GMS15 and GMS38/FAC composites (Li 2011). It is found that the density declines with the increase of LWF in the composites which was apparently expected because of the physical properties of the LWF particles (Table 1). The greater the LWF content, the lesser is the density. However, the decrement is more significant in case of GMS15 as compared to GMS18 and FAC. Only $10 \mathrm{wt} \%$ incorporation of GMS15 decreased the unit weight by about $40 \%$ while FAC and GMS38 could reduce it by only up to about $26 \%$ by 25 and $10 \mathrm{wt} \%$ addition, respectively. This was an indicative that GMS15 was better in producing lightweight cement composites as compared to GMS38 and FAC.

However, the decrease in the density directly influenced the mechanical properties of the composites. As comprehended from the Table 4, the compressive strength decreased drastically for GMS15 composites as compared other LWF composites (GMS38 and FAC). The compressive strength at 10-day age for GMS15 composites was too low to be determined due to the minimum stress limitation of the compression testing machine (5 MPa). For 28-day compressive strength values, it was found that the incorporation of $10 \%$ of GMS15 reduced the strength by more than $80 \%$ as compared to the control mix (CM) while with $30 \mathrm{wt} \%$ incorporation, the corresponding decline was about $94 \%$. This very low strength values were due to both the total air content (in the matrix) and required mixing water (to achieve uniformity and consistency of fresh mortar mix) associated with the LWF incorporation which were exacerbated by the lower isostatic crush strength $(2.07 \mathrm{MPa})$ of GMS15 particles. On the other hand, the composites with GMS38 and FAC showed much better mechanical performance. The strength decrease in GMS38 and FAC composites was found about 49 and $43 \%$ for LWF weight fraction of 10 and $25 \%$, respectively. It was interesting to see that 10 and $25 \mathrm{wt} \%$ incorporation of GMS38 and FAC, respectively resulted in composites having similar densities but the corresponding compressive strength was $6 \%$ higher for FAC composites.
Similar phenomenon had been observed for other levels of LWF weight fraction for these composites. Further, the total water content in the mixes varied which was also a factor in strength reduction as according to Abram's law (Abrams 1927), it directly influences the strength. The higher the water to cementitious materials ratio, the lower is the strength. However, it was seen that FAC modified composites exhibited better mechanical characteristics regardless of higher water content which is due to the chemical composition of FAC particles and tougher shell. All the FAC modified composites either had similar or higher water to binder ratio as compared to their GMS15 and GMS38 containing counterparts, still higher strength levels were achieved for these composites. This showed that FAC was superior to GMS38 and GMS15 in producing lightweight composites with better mechanical properties. Also, GMS38 have proved to be better than GMS15 in a similar way. Both the GMS15 and GMS 38 incorporated composites contained same water amount at the same weight fraction level of LWFs, but their mechanical performance particularly the compressive strength varied greatly.

The overall mechanical behavior of composites in terms of specific strength (defined as strength per unit weight) was depicted in Fig. 3. The significance of establishing the specific strength criterion lied in the correlation of density with compressive strength. The FAC and GMS38 composites exhibited linear drop in specific strength with increase of LWF weight fraction while the slope of GMS38 composites was much steeper. The lightest FAC, GMS38 and GMS15 composites had specific strength values of 30.66, 16.18 and $8.57 \mathrm{kPa} / \mathrm{kg} \mathrm{m}^{3}$ respectively. It meant that these composites correspond to the compressive strength of 73.58, 38.83 and $20.57 \mathrm{MPa}$, respectively for an equivalent cement composite (like typical mortar) having density of $2400 \mathrm{~kg} / \mathrm{m}^{3}$. The analysis of specific strength also showed the potential of FACs to be used for producing high strength composites while GMS15 are found useful for lightweight non-structural applications.

\subsection{Flexural and Tensile Behavior}

The flexural and tensile strength values were summarized in Table 4. Flexural strength was found varying in a similar fashion as was seen in compressive strength trend. However, the corresponding strain values differed in each case. For every $10 \mathrm{wt} \%$ increment of LWFs, the average corresponding decline in peak flexural strength of composites had been found as about 53, 34 and 15\% for GMS15, GMS38 and FAC, respectively. Moreover, all the LWFs used in the study showed excellent bonding with the PVA fiber-reinforced cementitious matrix. The flexural behavior of the LWF composites is shown in Fig. 5. It had been observed that PVA fibers were fully able to develop strain hardening in the composites, however the first cracking strength was governed by the matrix strength. Even though the fiber content was the same in all the composites, still the strain capacities values differed greatly which may be due to uneven fiber distribution in the mix and the nature of the corresponding 

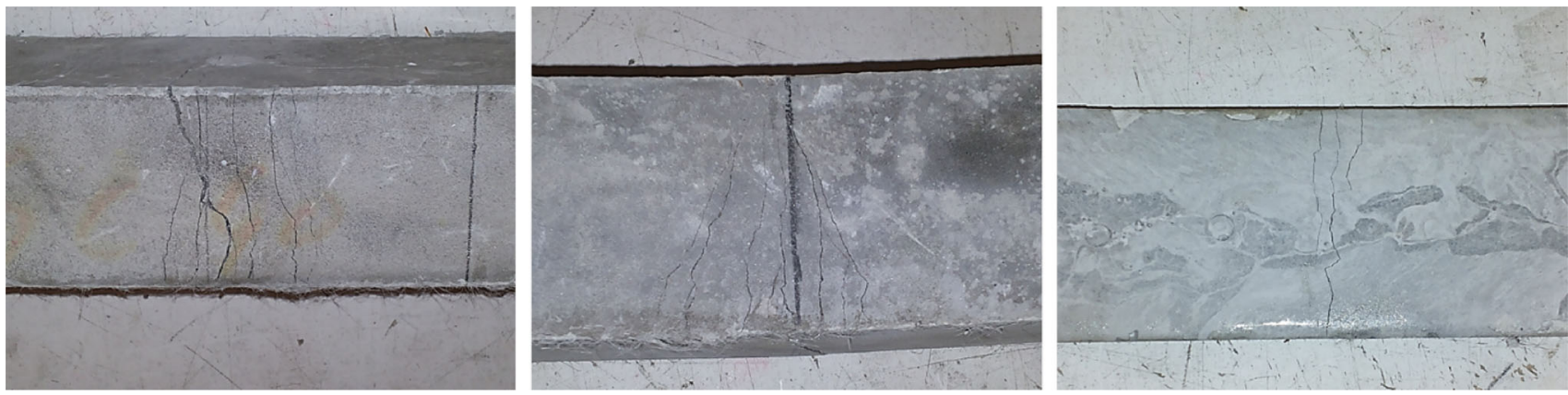

Fig. 4 Multiple-cracking behavior as seen in the failed specimen.

LWF. Figure 4 shows the cracking patterns obtained after the fracture of some of the specimens (Fig. 6).

All the FAC composites showed better post cracking behavior as compared to GMS15 and GMS38 modified composites. Although, at lower weight fraction of LWF (10\%), the composites containing GMS15 and GMS38 also behaved well with flexural strain capacity values of 0.75 and $1 \%$ respectively, but still it can be seen that after the first crack, the matrix wasn't able to sustain longer even with the help of fibers. The peak flexural strength values for composites with similar unit weight (GMS15-0.1, GMS38-0.2, and FAC-0.55) show that LWFs GMS15 and GMS38 behave in a similar fashion (mainly due to their similar chemical composition) while FAC incorporated composites expressed almost double the value as compared to others. However, it was found that GMS15 composites were more brittle in nature as compared to their counterparts (GMS38). The primary reason for such behavior was the thinner shell thickness (1-2 microns) and lower isostatic crushing strength value (Table 1). Moreover, it was pertinent to identify the loss of ductility in the composites with the increasing LWF content. This showed that using such LWFs in higher amounts, greater fiber weight fraction was needed if the desired characteristics of the composites required strain hardening. The strain capacity values for FAC modified composites were higher than the GMS15 and GMS38 incorporated composites due to the better bonding of FACs and fibers with the binder matrix. It was further confirmed and explained in microstructural investigations in Sect. 3.3.

The tensile properties are given in Table 4 and plotted in Fig. 8. These show a similar trend as have already been observed for flexural strength characteristics. Tensile strength is found almost one-third of the flexural strength for all the composites. The tensile strain capacity values have been found to be limited (maximum) at $0.40 \%$ for all the composites. But it could be seen that FAC incorporated composites could perform better in a similar way as was in case of flexural behavior but the tensile stress-strain curves are more confined and the first-crack strain is limited to $0.10 \%$ only. GMS15 particles breaking earlier lead to reduced strength and limited strain capacity values.

The ratio of compressive strength to tensile strength is low in comparison with the conventional mortar mixes. This is true because of the fillers used in the study are hollow spherical shells with different isostatic crushing strength

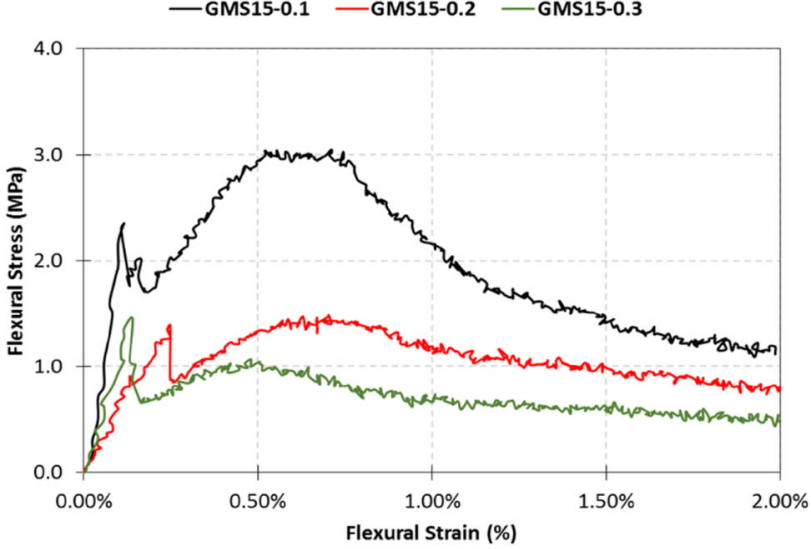

(a)

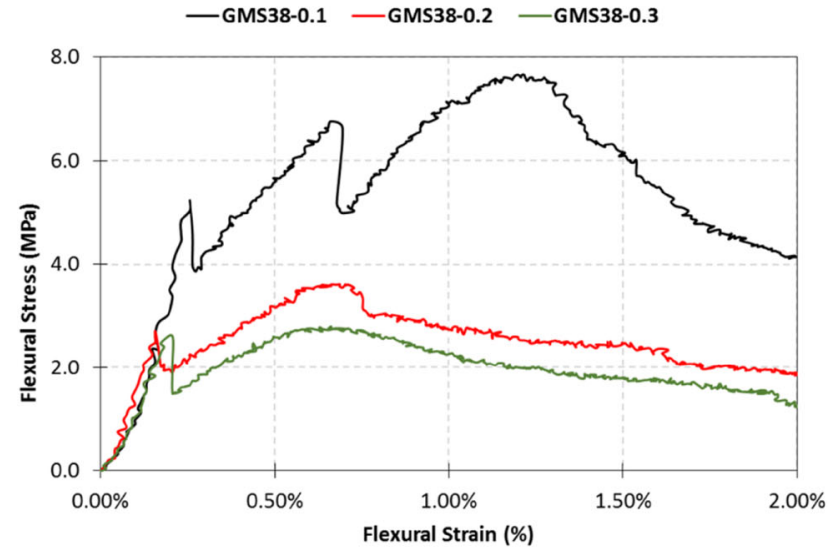

(b)

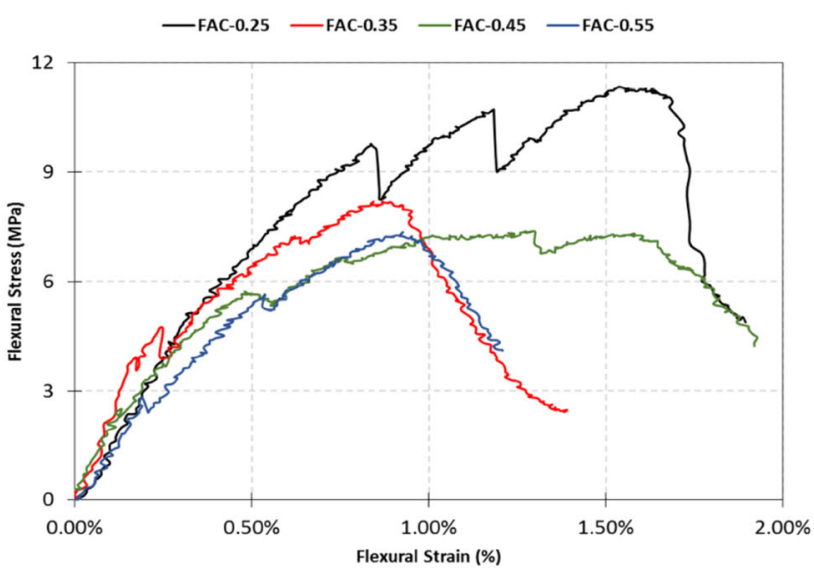

(c)

Fig. 5 Flexural stress versus flexural strain curves of composites at 28-day age. (Color figure online). 


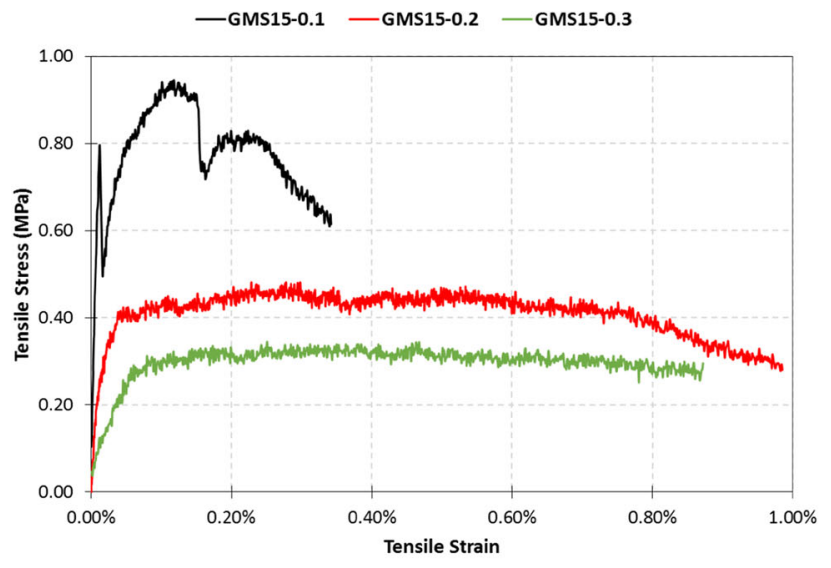

(a)

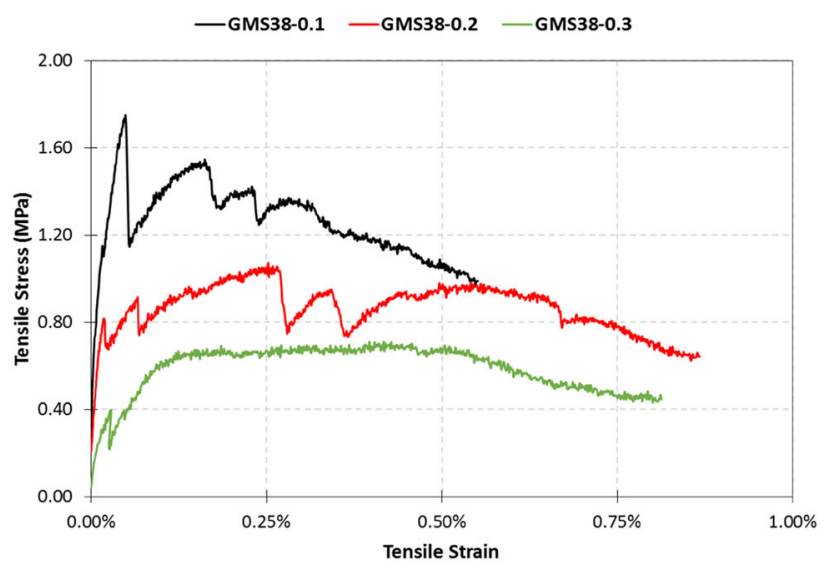

(b)

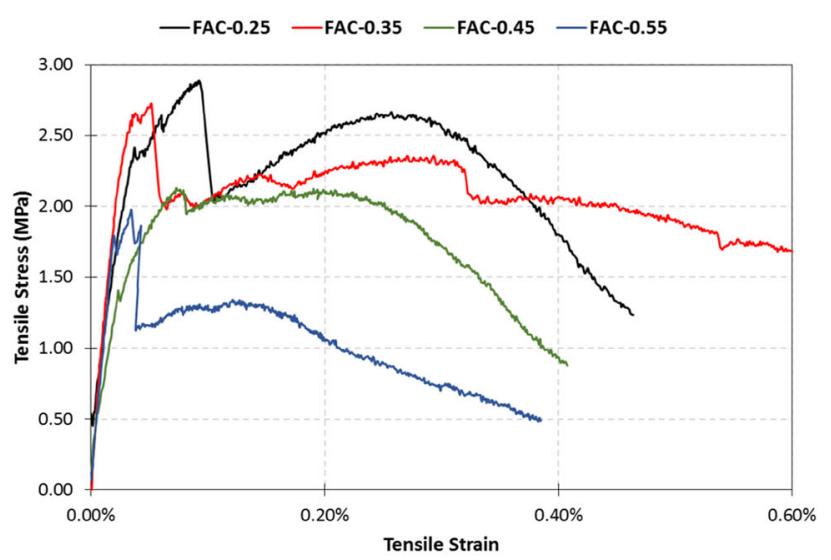

(c)

Fig. 6 Tensile stress versus tensile strain curves of composites at 28-day age. (Color figure online).

values (Table 1) which depend primarily on the hollow spherical shell thickness. Thus, the matrix strength is reduced with the inclusion of these particles which leads to the lower first cracking strength. The first crack strength as well as the ultimate strength of the composites found to be directly correlated to the isostatic crushing strength value which is dictated by the shell thickness $(1-2$ microns for GMS particles whereas several microns for FACs). Even the fibers were used to improve the tensile behavior, the lower matrix strength especially in case of composites modified with GMS particles hindered the development of pronounced strain hardening.

\subsection{Microstructural and Morphological Characterization}

The results of mercury intrusion porosimetry are summarized in Table 5 while the cumulative porosity and $\log$ differential intrusion volume curves are plotted in Figs. 7 and 8 , respectively. The porosity is a function of different parameters and it depends on the water content, amount of entrapped/entrained air (if any) and voids introduced in the composite due to the inclusion of LWF spherical particles. Porosity studies help to model and correlate various concrete properties e.g. the mechanical properties particularly elastic properties, fracture toughness, tensile strength, and compressive strength (Pereira et al. 1989; Rice 1998). The direct correlation of porosity with mechanical properties can be seen from the results which are expected due to the lightweight nature of the resulting composites (Figs. 9, 10). It could be seen that the porosity versus LWF weight fraction and porosity versus compressive strength trends are linear. This is in agreement with such relationship models already in the existing literature (Pereira et al. 1989). However, the slope of the curves for GMS15 and GMS38 was steeper than their counterpart i.e. FAC. This shows that a small amount of GMS particles would lead to more porous internal structure. FAC containing composites, regardless of higher water content, showed lower porosity values mainly due to the higher iso-static strength of these particles. The denser microstructure and better interfacial properties also helped reduce the total porosity.

An interesting observation is pointed out regarding the permeability. Even though the porosity increases with increase of LWF amount in the composites, the permeability varies differently. For all the composites containing LWFs except GMS15-0.3, the permeability was found lower than that of the control mix (46.67 milliDarcy). This might be due to the filling effect of the very small sized particles of LWFs. For GMS15-0.3, higher water content was used which is the primary reason of porosity related properties but the low shell strength of GMS15 particles is also another factor. The thinner shells which broke under compressive stresses led to ultimately higher porosity and permeability. It was, generally, seen that the permeability increased with increasing LWF amount in the composite. Although, the permeability values obtained from Katz-Thompson model were not accurate rather over-estimated for the composites under evaluation (Ma 2014; Ma et al. 2014) still the values could be used for comparative assessment.

The porosity doubled with the incorporation of 10 and $25 \mathrm{wt} \%$ of glass microspheres (GMS15 and GMS38) and FACs, correspondingly. However, with every $10 \mathrm{wt} \%$ increase of LWF content, the porosity increment observed was $14.66,6.76$, and $5.04 \%$ for GMS15, GMS38 and FACs. The apparent results on porosity could be attributed to two reasons; first, the greater number of pores associated with the higher water content and air voids within the composite, and second, the breakage of weak LWF particles (due to lower 
Table 5 Porosity and permeability values for the composites.

\begin{tabular}{c|c|c|c|c|c|c|c|c|c|c|c}
\hline Description & CM & GMS15-0.1 & GMS15-0.2 & GMS15-0.3 & GMS38-0.1 & GMS38-0.2 & GMS38-0.3 & FAC-0.25 & FAC-0.35 & FAC-0.45 & FAC-0.55 \\
\hline \hline Porosity (\%) & 17.68 & 36.91 & 50.23 & 66.23 & 36.07 & 42.08 & 49.60 & 36.25 & 39.34 & 45.30 & 51.37 \\
\hline $\begin{array}{c}\text { Permeability } \\
\text { (mDarcy) }\end{array}$ & 46.67 & 5.32 & 11.13 & 68.28 & 6.65 & 25.33 & 5.45 & 7.19 & 7.50 & 22.11 & 28.68 \\
\hline
\end{tabular}

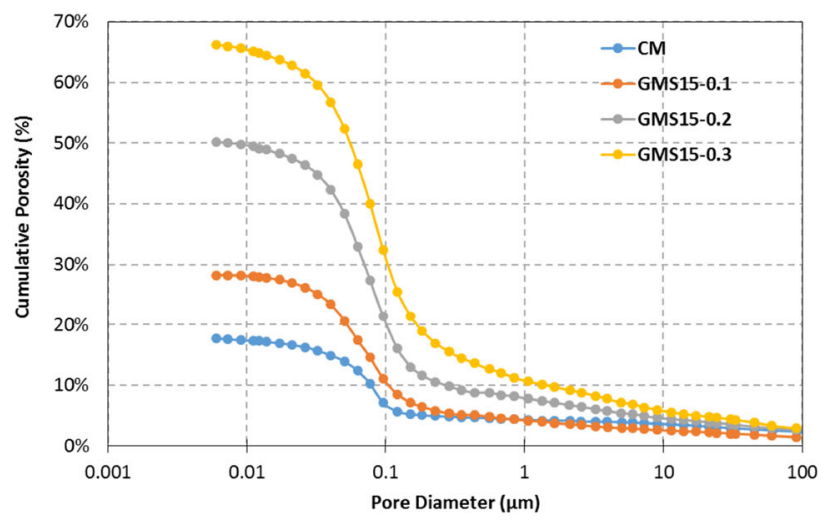

(a)

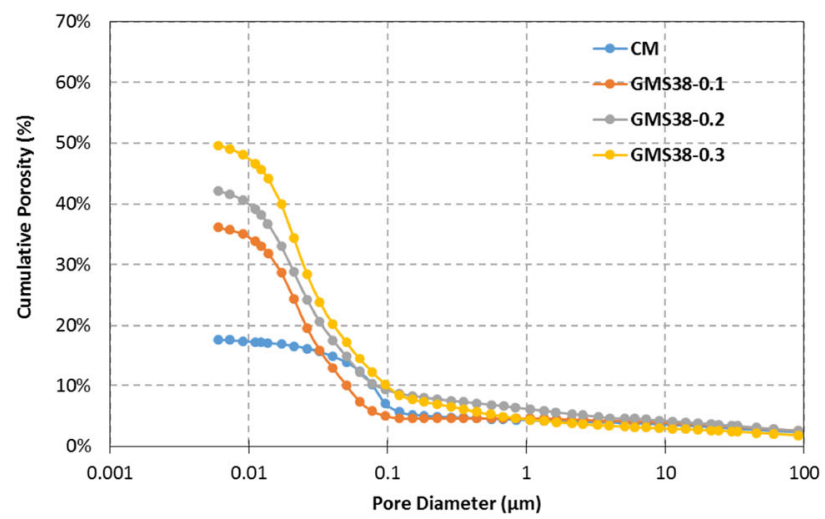

(b)

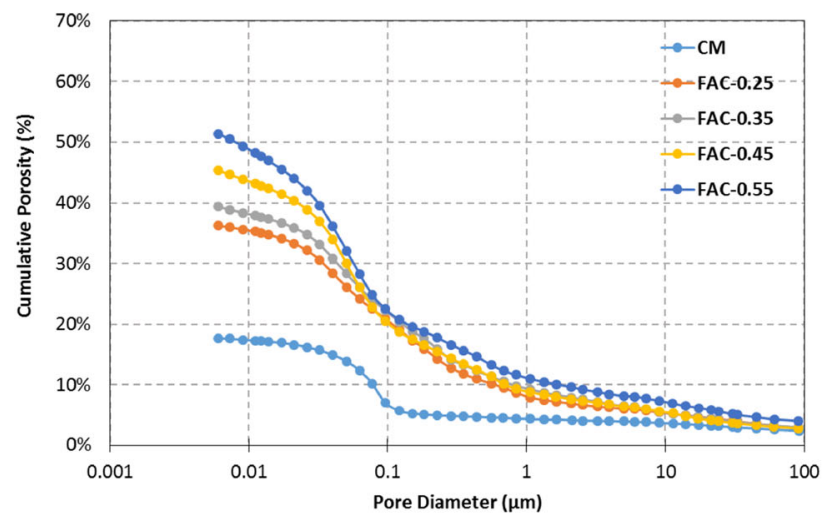

(c)

Fig. 7 MIP results expressed as cumulative porosity curve plots. (Color figure online).

iso-static crush strength representing thinner shell thickness) in the composites which led to greater mercury intrusion as some of the particles were of significantly larger size. It was evident from the MIP results that FACs and GMS38 were superior to GMS15. The correlation of porosity with mechanical strength (compressive strength) was linear for the composites. The critical diameter $\left(\mathrm{d}_{c}\right)$ was determined

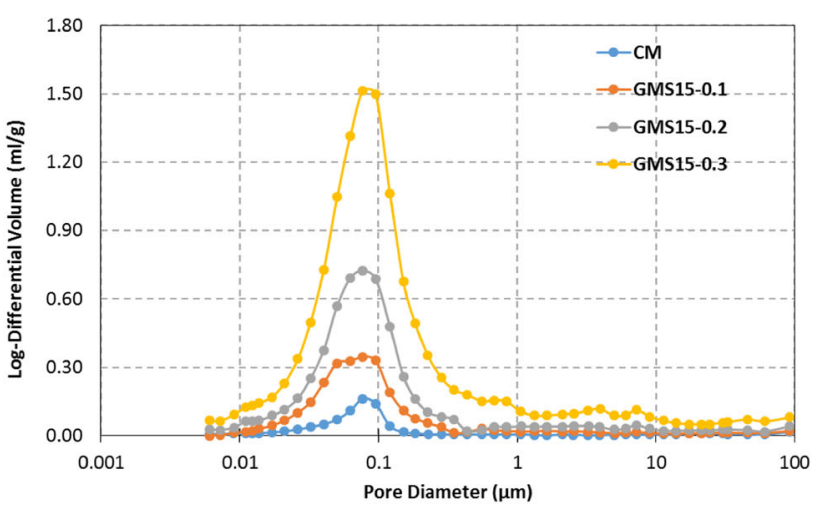

(a)

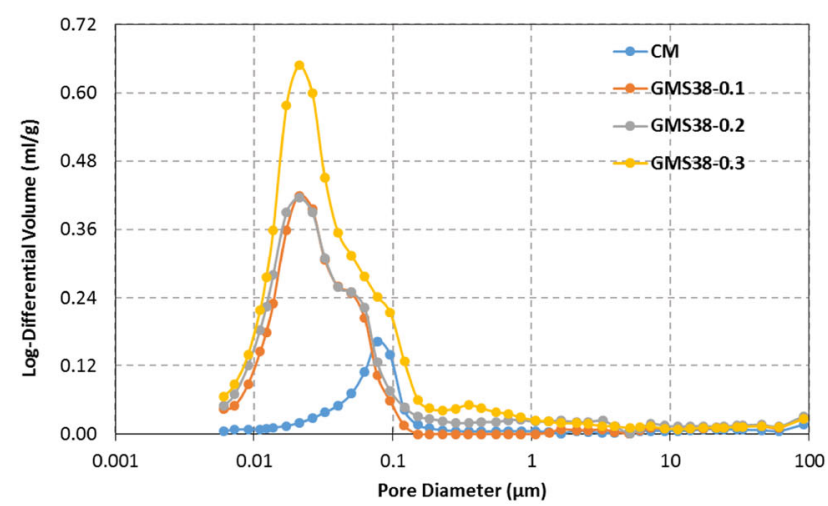

(b)

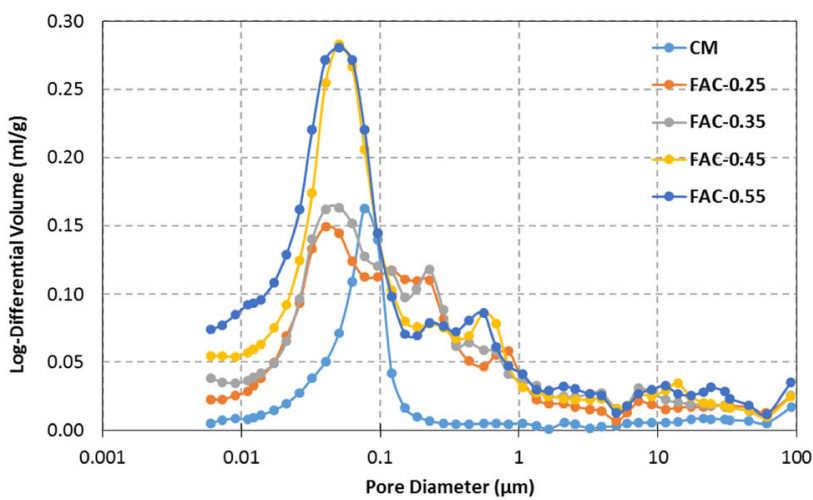

(c)

Fig. 8 Plots of log differential intrusion volume versus pore diameter. (Color figure online).

(from the $\log$ differential intrusion volume plot) as 0.07 , 0.02 , and $0.05 \mu \mathrm{m}$ for GMS15, GMS38, and FAC composites, respectively.

The critical diameter didn't change for one particular set of composites (containing the same LWF). The peak of log differential plot (corresponding to $d_{c}$ ) for all the LWF composites tends to shifts towards left (smaller pore 


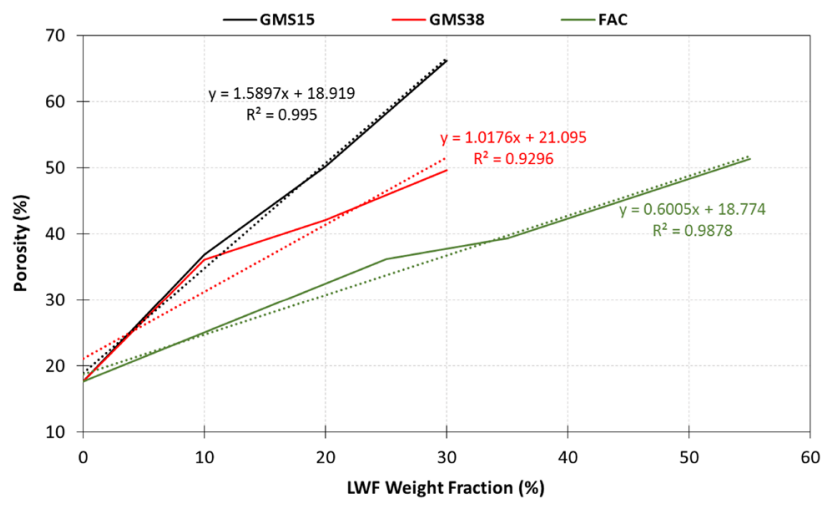

Fig. 9 MIP results summary indicating the total porosity with correlation of filler amount. (Color figure online).

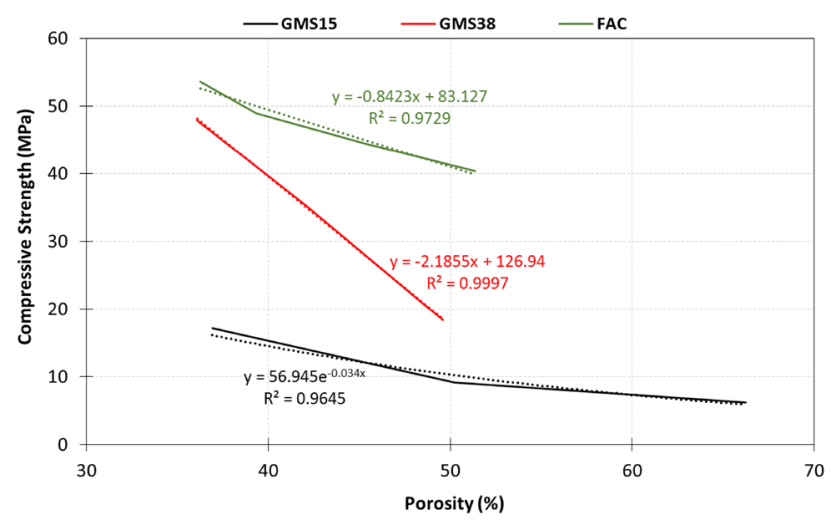

Fig. 10 Correlation of porosity with mechanical strength of composites incorporating LWFs. (Color figure online).

diameter range) in relation to that for CM. The greater mercury intrusion volume with increase of LWF weight fraction indicates a greater percentage of pore volume in the corresponding composites. Thus, it could be deduced that such composites would behave well for thermal insulation applications. The thermal conductivity coefficient of air $(1.008 \mathrm{~W} / \mathrm{m} \mathrm{K})$ is far lower than that of cement mortar (2.3), thus higher pore volume would lead to a reduced thermal conductivity coefficient. However, it could be seen that incorporation of glass microspheres lead to a more porous microstructure which can be more meaningful for thermal insulating applications whereas the corresponding composites have reduced mechanical strength too. This suggests that in order to achieve a balance of different characteristics, a blend of these fillers may be helpful.

The results of thermogravimetric analyses are shown in the Figs. 11 and 12. It could be see that all the composites were fairly stable up to a high temperature range. The dehydroxylation and decarbonation peaks were identified from the differential thermogravimetric plots and the corresponding temperature ranges were 400-500 and 800-900 ${ }^{\circ} \mathrm{C}$, respectively. Both the dehydroxylation and decarbonation phases showed that FAC composites decomposed (indicative of reactivity of FAC particles) more in relation to GMS modified composites. The greater weight loss of the specimen shows higher decomposition of calcium hydroxide and calcium carbonate form the hydration

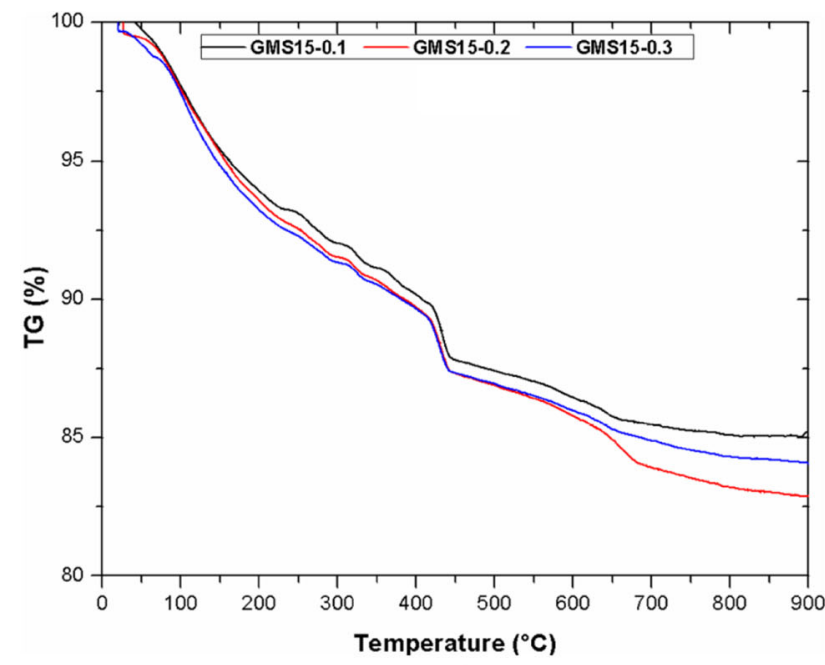

(a)

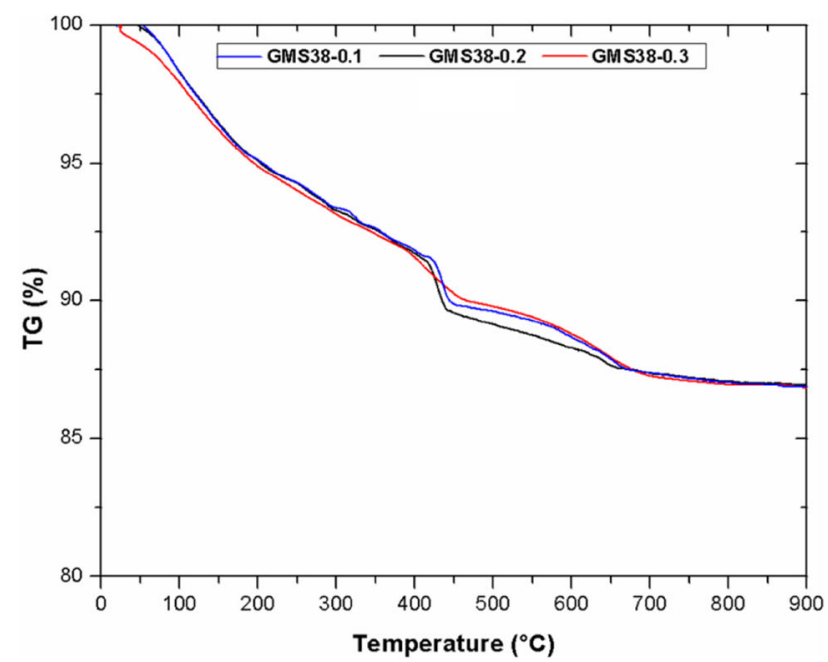

(b)

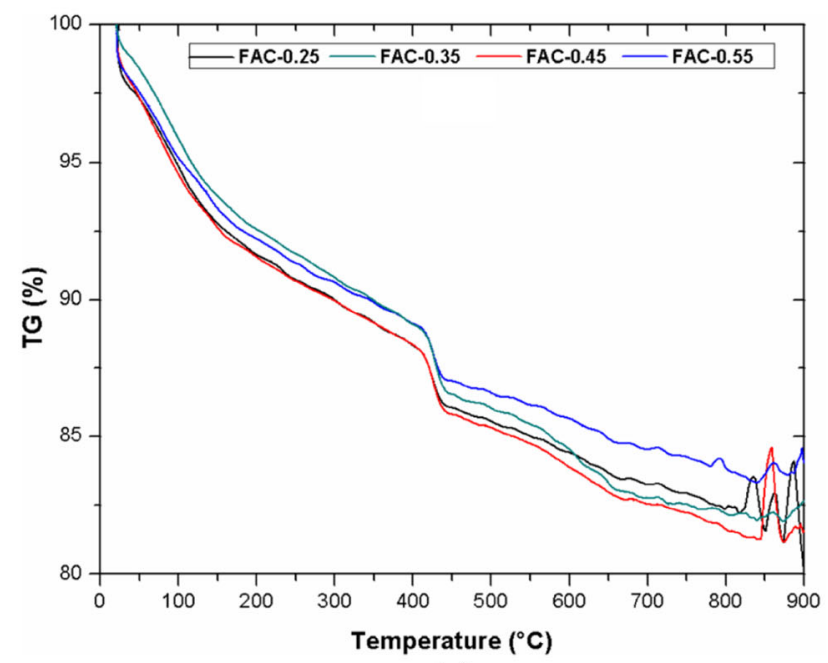

(c)

Fig. 11 TGA weight loss curves for various composites incorporating fillers; a GMS15, b GMS38, and c FAC. (Color figure online).

products. Even though the remaining weight percent of GMS38 incorporated composites $(86.90 \%)$ was higher than their corresponding counterparts with GMS15 as LWF, still 


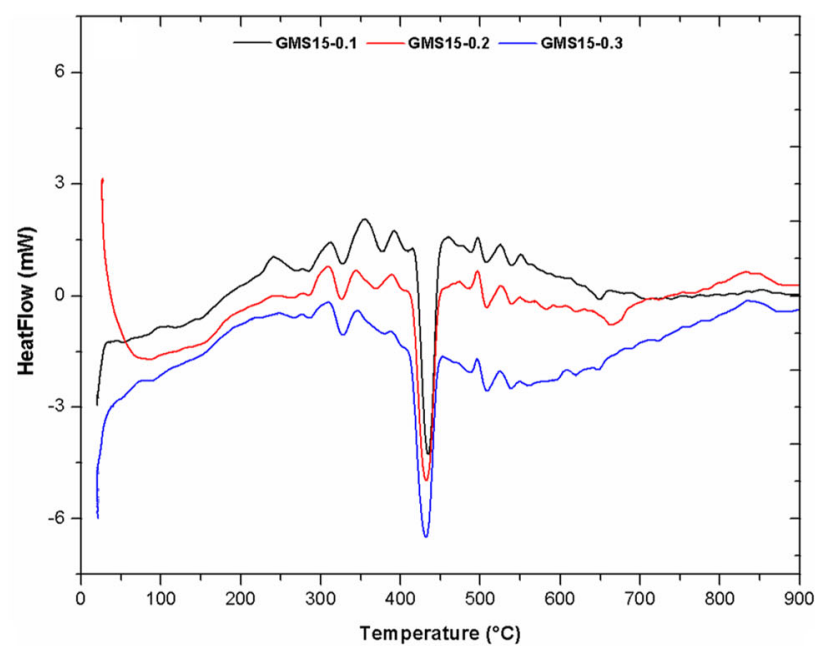

(a)

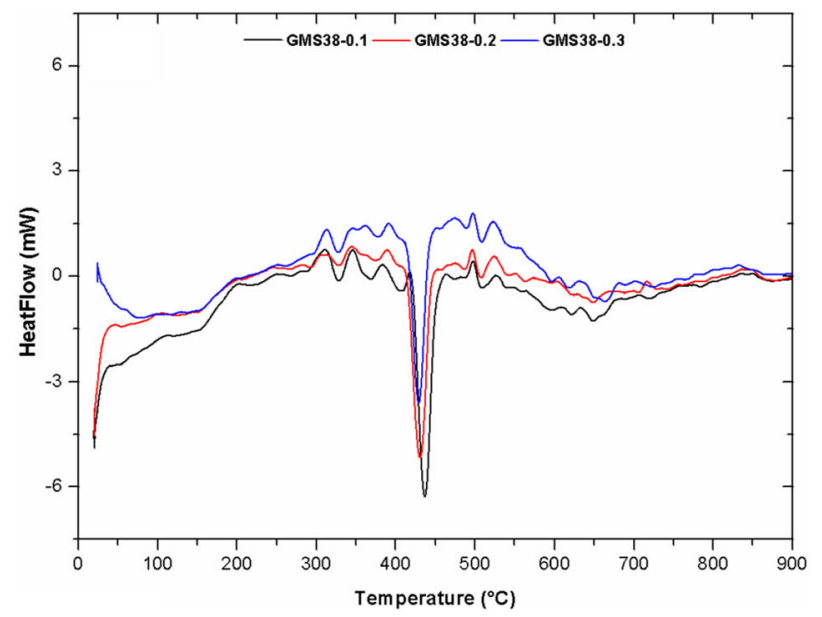

(b)

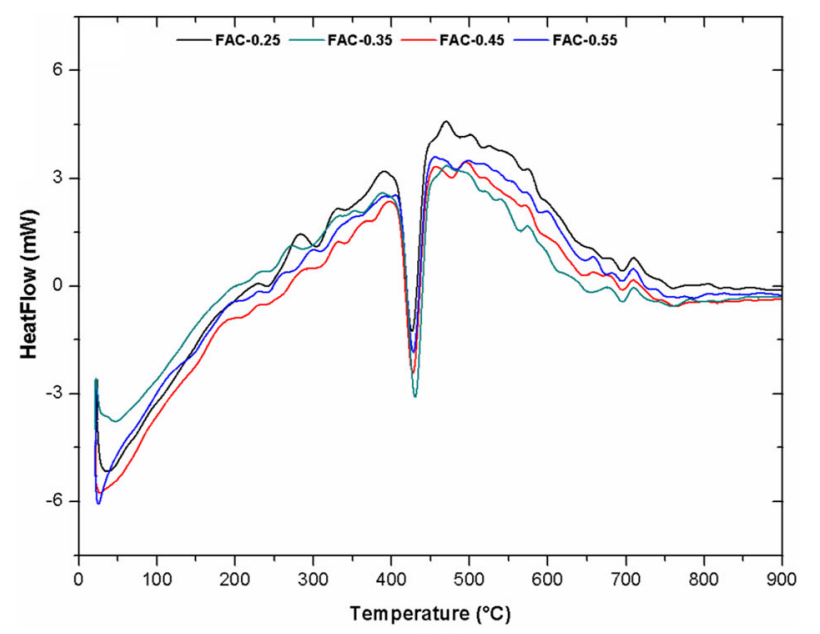

(c)

Fig. 12 TGA weight loss curves for various composites incorporating fillers; a GMS15, b GMS38, and c FAC. (Color figure online).

these composites yielded better mechanical strength which is attributed to the individual particle characteristics.

The SEM micrographs are presented in Figs. 13 and 14. GMS15 modified composites were found relatively more
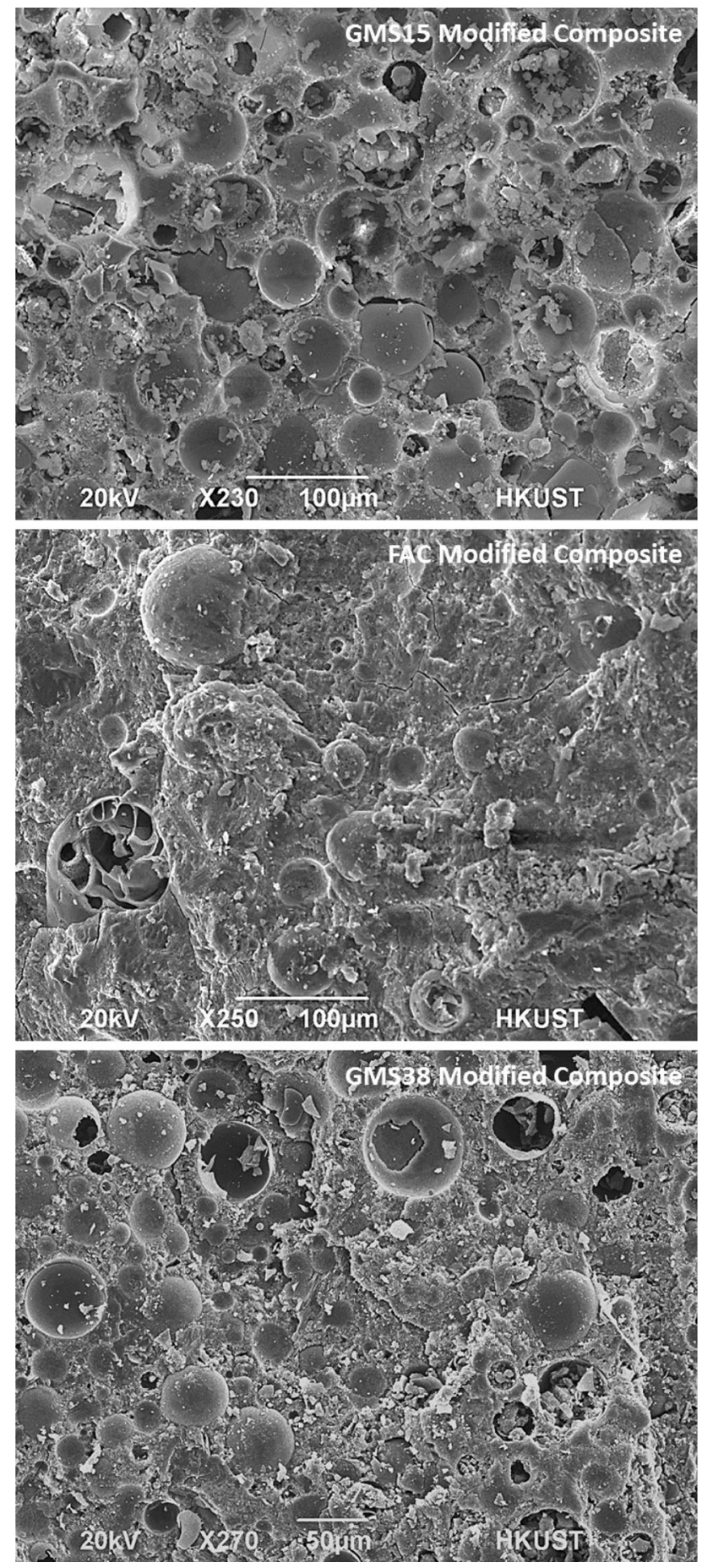

Fig. 13 SEM images of fractured surfaces of composites containing LWFs.

porous. Further, the GMS15 particles were observed mostly broken inside the composite structure. The low mechanical strength of these particles could not help the particles to resist the stresses within the composites. On the other hand, the composites incorporating GMS38 particles showed a different behavior. It could be seen that the crack growth was resisted by the GMS38 particles by hindering its path. However, some of the particles did break. Moreover, the weak ITZ (interfacial transition zone) characteristics were observed too.

FAC bearing composites could be seen the most dense among all the composites. The FACs bonded exceptionally 

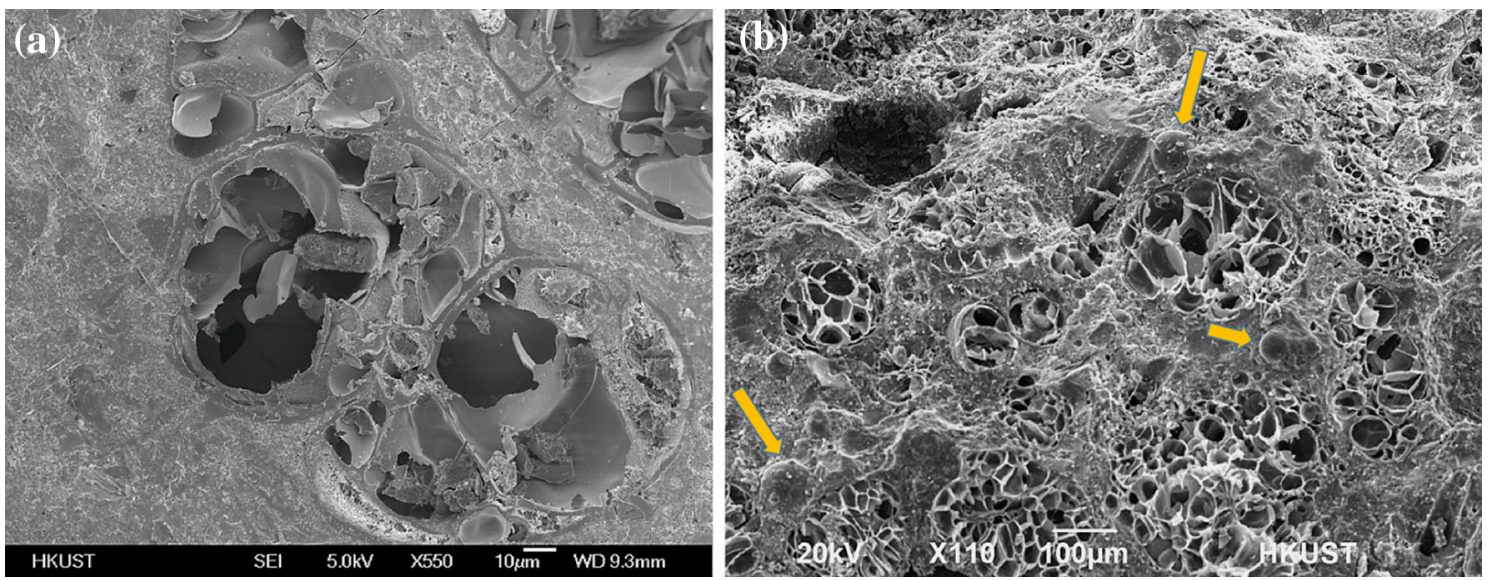

Fig. 14 Partial reactivity of FAC particles observed in a cement paste, and b FAC modified composite used in this study; (arrows indicating unreacted particles).

well with the cementitious matrix thus improving the properties. However, partially consumed (not broken) FAC shells were also seen in SEM imagery which is due to the partial reactivity of FAC particles owing to the presence of amorphous silica and some percentage of lime. The partially consumed FAC particles observed along with the unreacted ones are shown in the SEM images in Fig. 13. The reactivity could be responsible for higher compressive strength even at larger levels of FAC addition. This is so because the pozzolanic reaction leads to greater calcium silicate hydrate (CSH) gel in the system. The denser, more compacted, and uniform microstructure in the FAC modified composites influenced certain other properties of the composites including the post-first-crack behavior, flexural and tensile strain capacity, and total porosity. Primarily, the lime and amorphous silica present in the FACs is responsible for denser microstructure due to the increased pozzolanic activity. The pozzolanic reactivity can be further assessed from the dehydroxylation and decarbonation peaks obtained in TGA, already discussed earlier.

\section{Conclusions}

A comprehensive and thorough study on the cement-based composites incorporating various types of lightweight functional fillers (LWFs), including fly ash cenosphere (FAC) and glass microsphere (GMS15 and GMS38), was conducted to evaluate the influence of the LWFs on various properties of the corresponding lightweight composites and asses their feasibility in different building structural applications. Both mechanical and microstructural properties were studied. The results indicated that both FAC and GMS38 were suitable for producing structural lightweight composites (density less than $1920 \mathrm{~kg} / \mathrm{m}^{3}$ and minimum compressive strength of $17 \mathrm{MPa}$ (ACI 213 2003)).

Following conclusions are drawn from the current study. (a) FACs and GMS38 particles proved to be excellent materials for producing lightweight and ultra-lightweight cementitious composites. They can be employed for structural (load-carrying) purposes where higher mechanical strength is required, as long as they are incorporated in reasonable proportions in the composites. On the other hand GMS15 are inadequate due to weaker shell (or more specifically, the iso-static crush strength).

(b) Given the decent strength to unit weight ratio, FAC and GMS38 are suitable for producing precast non loadbearing members like, wall panels, partition walls, ceiling, etc. However, GMS15 are not adequate to be used for such applications because of much lower mechanical strength associated with the resulting composites.

(c) FACs and GMS38 are well suited for fiber-reinforced composites to efficiently utilize the tensile properties of fibers. Good bonding in the fibrous mortars leading to excellent ductility indicates their promising use for fiber-reinforced composites. Whereas GMS15 particles couldn't be very helpful in this regard due to the weakness of their shell which may break earlier under stresses.

(d) Glass microspheres, both GMS15 and GMS38, are good candidates for producing thermal insulating composites due to the greater pore volume associated with their incorporation, however they should be added with other materials/fillers (e.g. FAC) to achieve better mechanical properties.

(e) The adequate weight fraction of these LWFs to be incorporated in the cement composites is determined as $20,55 \%$, and less than $10 \%$ for GMS38, FACs, and GMS15, respectively. Greater amounts may pose higher permeability and porosity leading to reduced mechanical properties thus restricting the possible use. 


\section{Acknowledgements}

This work was financially supported by the China Ministry of Science and Technology under Grant 2015CB655100. The authors would also thank Advanced Engineering Manufacturing Facility (AEMF) at HKUST for providing technical support for surface area measurement (using nitrogen adsorption method) of the LWFs used in this study.

\section{Open Access}

This article is distributed under the terms of the Creative Commons Attribution 4.0 International License (http://creativecommons.org/licenses/by/4.0/), which permits unrestricted use, distribution, and reproduction in any medium, provided you give appropriate credit to the original author(s) and the source, provide a link to the Creative Commons license, and indicate if changes were made.

\section{References}

Abbas, S., Nehdi, M. L., \& Saleem, M. A. (2016). Ultra-high performance concrete: Mechanical performance, durability, sustainability and implementation challenges. International Journal of Concrete Structures and Materials, 10(3), 271-295. doi:10.1007/s40069-016-0157-4.

Abrams, D. A. (1927). Water-cement ratio as a basis of concrete quality. ACI Journal Proceedings, 23(2), 452-457.

ACI 216.1. (1997). Standard method for determining fire resistance of concrete and masonry construction assemblies.

ACI 213. (2003). Guide for structural lightweight-aggregate concrete.

ACI Committee 318. (2007). Building code requirements for structural concrete (ACI 318M-08) (Vol. 2007).

ASTM C 1437-99. (1999). Standard test method for flow of hydraulic cement mortar. American Society for Testing and Materials, 1-2. doi:10.1520/C1437-13.2

ASTM C230. (2003). Standard specification for flow table for use in tests of hydraulic cement. American Society for Testing and Materials. doi:10.1520/C0230

ASTM D790-10. (2010). Standard test methods for flexural properties of unreinforced and reinforced plastics and electrical insulating materials. American Society for Testing and Materials. doi:10.1520/D0790-10

Bouvard, D., Chaix, J. M., Dendievel, R., Fazekas, A., Létang, J. M., Peix, G., et al. (2007). Characterization and simulation of microstructure and properties of EPS lightweight concrete. Cement and Concrete Research, 37(12), 1666-1673. doi:10.1016/j.cemconres.2007.08.028.

Chandra, S., \& Berntsson, L. (2002). Lightweight aggregate concrete: Science, technology, and applications. Norwich, NY: Noyes Publications/William Andrew Publishing.
Chávez-Valdez, A., Arizmendi-Morquecho, A., Vargas, G., Almanza, J. M., \& Alvarez-Quintana, J. (2011). Ultra-low thermal conductivity thermal barrier coatings from recycled fly-ash cenospheres. Acta Materialia, 59(6), 2556-2562. doi:10.1016/j.actamat.2011.01.011.

Chen, B., \& Liu, N. (2013). A novel lightweight concrete-fabrication and its thermal and mechanical properties. Construction and Building Materials, 44(2013), 691-698. doi: 10.1016/j.conbuildmat.2013.03.091.

de Gennaro, R., Langella, A., D’Amore, M., Dondi, M., Colella, A., Cappelletti, P., et al. (2008). Use of zeolite-rich rocks and waste materials for the production of structural lightweight concretes. Applied Clay Science, 41(1-2), 61-72. doi:10.1016/j.clay.2007.09.008.

Demirboğa, R., Örüng, I., \& Gül, R. (2001). Effects of expanded perlite aggregate and mineral admixtures on the compressive strength of low-density concretes. Cement and Concrete Research, 31(11), 1627-1632. doi: 10.1016/S0008-8846(01)00615-9.

Ducman, V., \& Mladenovic, A. (2004). Alkali-silica reactivity of some frequently used lightweight aggregates. Cement and Concrete Research, 34(2004), 1809-1816. doi: 10.1016/j.cemconres.2004.01.017.

$3 \mathrm{M}$ Energy and Advanced Materials Division. $3 \mathrm{M}^{\mathrm{TM}}$ glass microspheres compounding and injection molding guidelines (2007). http://multimedia.3m.com/mws/media/ 426234O/3mtm-glass-microspheres-compounding-and-injmolding-guide.pdf

Gao, T., Jelle, B. P., Gustavsen, A., \& Jacobsen, S. (2014). Aerogel-incorporated concrete: An experimental study. Construction and Building Materials, 52(2014), 130-136. doi:10.1016/j.conbuildmat.2013.10.100.

Hanif, A., Diao, S., Lu, Z., Fan, T., \& Li, Z. (2016). Green lightweight cementitious composite incorporating aerogels and fly ash cenospheres-Mechanical and thermal insulating properties. Construction and Building Materials, 116, 422-430. doi:10.1016/j.conbuildmat.2016.04.134.

Hassanpour, M., Shafigh, P., \& Mahmud, H. Bin. (2012). Lightweight aggregate concrete fiber reinforcement-A review. Construction and Building Materials, 37, 452-461. doi:10.1016/j.conbuildmat.2012.07.071.

Katz, A. J., \& Thompson, A. H. (1986). Quantitative prediction of permeability in porous rock. Physical Review B, 34(11), 8179-8181. doi:10.1103/PhysRevB.34.8179.

Ke, Y., Beaucour, A. L., Ortola, S., Dumontet, H., \& Cabrillac, R. (2009). Influence of volume fraction and characteristics of lightweight aggregates on the mechanical properties of concrete. Construction and Building Materials, 23(8), 2821-2828. doi:10.1016/j.conbuildmat.2009.02.038.

Kim, S., Seo, J., Cha, J., \& Kim, S. (2013). Chemical retreating for gel-typed aerogel and insulation performance of cement containing aerogel. Construction and Building Materials, 40, 501-505. doi:10.1016/j.conbuildmat.2012.11.046.

Kramar, D., \& Bindiganavile, V. (2010). Mechanical properties and size effects in lightweight mortars containing expanded perlite aggregate. Materials and Structures, 44(4), 735-748. doi:10.1617/s11527-010-9662-0. 
Kramar, D., \& Bindiganavile, V. (2013). Impact response of lightweight mortars containing expanded perlite. Cement \& Concrete Composites, 37(2013), 205-214. doi: 10.1016/j.cemconcomp.2012.10.004.

Kwan, A. K. H., \& Chen, J. J. (2013). Adding fly ash microsphere to improve packing density, flowability and strength of cement paste. Powder Technology, 234(2013), 19-25. doi:10.1016/j.powtec.2012.09.016.

Lanzón, M., \& García-Ruiz, P. A. (2008). Lightweight cement mortars: Advantages and inconveniences of expanded perlite and its influence on fresh and hardened state and durability. Construction and Building Materials, 22(8), 1798-1806. doi:10.1016/j.conbuildmat.2007.05.006.

Li, Z. (2011). Advanced concrete technology. New York, NY: Wiley.

Lotfy, A., Hossain, K. M. A., \& Lachemi, M. (2015). Lightweight self-consolidating concrete with expanded shale aggregates: Modelling and optimization. International Journal of Concrete Structures and Materials, 9(2), 185-206. doi:10.1007/s40069-015-0096-5.

Lowell, S., \& Shields, J. E. (1991). Powder surface area and porosity (3rd ed.). London, UK: Chapman and Hall Ltd. doi:10.1007/978-94-015-7955-1.

Lu, Z., Xu, B., Zhang, J., Zhu, Y., Sun, G., \& Li, Z. (2014). Preparation and characterization of expanded perlite/paraffin composite as form-stable phase change material. Solar Energy, 108, 460-466. doi:10.1016/j. solener.2014.08.008.

Ma, H. (2014). Mercury intrusion porosimetry in concrete technology: Tips in measurement, pore structure parameter acquisition and application. Journal of Porous Materials, 21(2), 207-215. doi:10.1007/s10934-013-9765-4.

Ma, H., Hou, D., Liu, J., \& Li, Z. (2014). Estimate the relative electrical conductivity of C-S-H gel from experimental results. Construction and Building Materials, 71, 392-396. doi:10.1016/j.conbuildmat.2014.08.036.

Ma, H., \& Li, Z. (2013). Realistic pore structure of Portland cement paste: Experimental study and numerical simulation. Computers \& Concrete, 11(4), 317-336. doi: 10.12989/cac.2013.11.4.317.

Mala, K., Mullick, A. K., Jain, K. K., \& Singh, P. K. (2013). Effect of relative levels of mineral admixtures on strength of concrete with ternary cement blend. International Journal of Concrete Structures and Materials, 7(3), 239-249. doi:10.1007/s40069-013-0049-9.

Miled, K., Sab, K., \& Le Roy, R. (2007). Particle size effect on EPS lightweight concrete compressive strength: Experimental investigation and modelling. Mechanics of Materials, 39(3), 222-240. doi:10.1016/j.mechmat.2006.05.008.

Ng, S., Jelle, B. P., Sandberg, L. I. C., Gao, T., \& Wallevik, Ó. H. (2015). Experimental investigations of aerogel-incorporated ultra-high performance concrete. Construction and Building Materials, 77, 307-316. doi:10.1016/j.conbuild mat.2014.12.064.

Palik, E. S. (1977). Specific surface area measurements on ceramic powders. Powder Technology, 18, 45-48.

Pereira, C. J., Rice, R. W., \& Skalny, J. P. (1989). Pore structure and its relationship to properties of materials. In $\mathrm{L}$. R. Roberts \& J. P. Skalny (Eds.), Materials research society symposium proceedings (Vol. 137, pp. 3-21). Pittsbutrgh, PA: Materials Research Society.

Pichór, W. (2009). Properties of fiber reinforced cement composites with cenospheres from coal ash. Brittle Matrix Composites, 9, 245. doi:10.1533/978184569775 4.245 .

Rashad, A. M., Seleem, H. E. D. H., \& Shaheen, A. F. (2014). Effect of silica fume and slag on compressive strength and abrasion resistance of HVFA concrete. International Journal of Concrete Structures and Materials, 8(1), 69-81. doi: 10.1007/s40069-013-0051-2.

Rice, R. W. (1998). Porosity of ceramics: Properties and applications. Boca Raton, FL: CRC Press.

Saradhi Babu, D., Ganesh Babu, K., \& Wee, T. H. (2005). Properties of lightweight expanded polystyrene aggregate concretes containing fly ash. Cement and Concrete Research, 35(6), 1218-1223. doi:10.1016/j. cemconres.2004.11.015.

Sharifi, Y., Afshoon, I., Firoozjaei, Z., \& Momeni, A. (2016). Utilization of waste glass micro-particles in producing selfconsolidating concrete mixtures. International Journal of Concrete Structures and Materials. doi:10.1007/s40069016-0141-z.

Spiesz, P., Yu, Q. L., \& Brouwers, H. J. H. (2013). Development of cement-based lightweight composites-Part 2: Durability-related properties. Cement \& Concrete Composites, 44(2013), 30-40. doi:10.1016/j.cemconcomp. 2013.03.029.

Topçu, İ. B., \& Işıkdağ, B. (2008). Effect of expanded perlite aggregate on the properties of lightweight concrete. Journal of Materials Processing Technology, 204(1-3), 34-38. doi: 10.1016/j.jmatprotec.2007.10.052.

Wang, J.-Y., Chia, K.-S., Liew, J.-Y. R., \& Zhang, M.-H. (2013). Flexural performance of fiber-reinforced ultra lightweight cement composites with low fiber content. Cement \& Concrete Composites, 43, 39-47. doi: 10.1016/j.cemconcomp.2013.06.006.

Wang, J. Y., Yang, Y., Liew, J. Y. R., \& Zhang, M. H. (2014). Method to determine mixture proportions of workable ultra lightweight cement composites to achieve target unit weights. Cement \& Concrete Composites, 53, 178-186. doi:10.1016/j.cemconcomp.2014.07.006.

Wang, J. Y., Zhang, M. H., Li, W., Chia, K. S., \& Liew, R. J. Y. (2012). Stability of cenospheres in lightweight cement composites in terms of alkali-silica reaction. Cement and Concrete Research, 42(5), 721-727. doi:10.1016/j.cemco nres.2012.02.010.

Washburn, E. W. (1921). Note on a method of determining the distribution of pore sizes in a porous material. Proceedings of the National Academy of Sciences of the United States of America, 7(4), 115-116. doi:10.1073/pnas.7.4.115.

Woignier, T., \& Phalippou, J. (1988). Mechanical strength of silica aerogels. Journal of Non-Crystalline Solids, 100(1-3), 404-408. doi:10.1016/0022-3093(88)90054-3.

Wu, Y., Wang, J.-Y., Monteiro, P. J. M., \& Zhang, M.-H. (2015). Development of ultra-lightweight cement composites with low thermal conductivity and high specific strength for energy efficient buildings. Construction and Building 
Materials, $\quad 87, \quad 100-112$ doi:10.1016/j.conbuildmat. 2015.04.004.

$\mathrm{Xu}$, B., Ma, H., \& Hu, C. (2015). Influence of cenospheres on properties of magnesium oxychloride cement-based composites. Materials and Structures. doi:10.1617/s11527-015-05 78-6.
Yu, Q. L., Spiesz, P., \& Brouwers, H. J. H. (2013). Development of cement-based lightweight composites-Part 1: Mix design methodology and hardened properties. Cement \& Concrete Composites, 44(2013), 17-29. doi:10.1016/j. cemconcomp.2013.03.030. 